\title{
Academic Supervision untuk Meningkatkan Learning Design Skills Guru di Sekolah Dasar
}

\author{
H. Muhsin \\ Pengawas TK/SD, Dinas Pendidikan Kabupaten Loteng Tengah - Provinsi NTB \\ Corresponding Author. Email: hmuhsin675@gmail.com
}

\begin{abstract}
The study was conducted to analyze the impact of academic supervision on improving teacher performance in the learning design process. The action research method was used to apply academic supervision and was designed in three cycles. Data were collected through 17 elementary school teachers from 10 supervisory schools in North Batukliang sub-district, Central Lombok Regency and analyzed quantitatively-descriptively. This study found that the implementation of continuous academic supervision was able to improve the learning design skills of elementary school teachers. In cycle-I as many as $41.17 \%$ of teachers have a good performance in learning design, in cycle-II there are $35.29 \%$ of teachers needing guidance, then in cycle-III all teachers meet standard skills in designing learning well $(100 \%)$. The results concluded that academic supervision has a positive effect on improving teacher performance in elementary schools
\end{abstract}

\begin{abstract}
Abstrak: Penelitian ini dilakukan untuk menganalisis dampak academic supervision terhadap peningkatan kinerja guru pada proses learning design. Metode yang digunakan merupakan action research dalam rangka menerapkan academic supervison. Rancangan penelitian tindakan dilakukan sebanyak tiga siklus. Pengumpulan data dilakukan terhadap 17 orang guru sekolah dasar yang berasal dari 10 sekolah binaan di kecamatan Batukliang Utara, Kabupaten Lombok Tengah dan diolah menggunakan analisis kuantitatif-deskriptif. Penelitian ini menemukan bahwa penerapan academic supervision secara kontinyu mampu meningkatkan learning design skills guru-guru sekolah dasar. Dampak academic supervision pada siklus I sebanyak $41,17 \%$ guru memiliki kinerja baik dalam merancang pembelajaran, sedangkan pada siklus II masih ada $35,29 \%$ orang guru yang membutuhkan bimbingan, selanjutnya di siklus III semua guru $(100 \%)$ telah memenuhi skil standar dalam merancang pembelajaran dengan baik. Hasil ini dapat disimpulkan bahwa academic supervision telah berpengaruh positif pada peningkatan kinerja guru di sekolah dasar.
\end{abstract}

\section{Article History}

Received: 02-01-2021

Revised: $18-02-2021$

Accepted: 22-03-2021

Published: 07-07-2021

\section{Key Words:}

Academic

Supervision, Learning

Design, Teachers'

Performance.

\section{Sejarah Artikel}

Diterima: 02-01-2021

Direvisi: 18-02-2021

Disetujui: 22-03-2021

Diterbitkan: 07-07-2021

\section{Kata Kunci:}

Academic Supervision, Learning Design, Kinerja Guru.

How to Cite: Muhsin, H. (2021). Academic Supervision untuk Meningkatkan Learning Design Skills Guru di Sekolah Dasar. Jurnal Paedagogy, 8(3), 282-287. doi:https://doi.org/10.33394/jp.v8i3.3823

\section{Pendahuluan}

Skil guru dalam melakukan desain pembelajaran sangat diperlukan untuk meningkatkan kinerjanya (Persico, et. al., 2020; Dagnino, et. al., 2018). Tanpa skil yang baik maka akan mengganggu tercapainya pembelajaran, oleh karena itu, skil guru dalam mendesain/merancang pembelajaran yang baik merupakan salah satu kempetensi wajib karena termasuk ke dalam kompetensi pedagogik guru.

Rancangan pembelajaran merupakan tindakan pengembangan secara sistematis dari spesifikasi pembelajaran dengan menggunakan teori belajar dan pembelajaran untuk menjamin kualitas pembelajaran (Ma, et. al., 2020). Proses perancangan dan pengembangan ini meliputi segala proses analisis kebutuhan pembelajaran, tujuan dan pengembangan sistem untuk mencapai tujuan, pengembangan bahan dan aktivitas pembelajaran, uji coba dan 
evaluasi dari seluruh pembelajaran dan aktivitas peserta didik. Beberapa model rancangan pembelajaran diantaranya adalah model Dick and Carey serta model ADDIE (West, et al., 2018; Gray, et al., 2015). Model ini termasuk ke dalam model prosedural.

Rancangan pembelajaran lazimnya dimulai dari kegiatan analisis yang digunakan untuk menggambarkan masalah pembelajaran sesungguhnya yang perlu dicari solusinya. Setelah dapat menentukan masalah yang sesungguhnya maka langkah selanjutnya adalah menentukan alternaif solusi yang akan digunakan untuk mengatasi masalah pembelajaran. Seorang perancang program pembelajaran perlu menentukan solusi yang tepat dari berbagai alternatif yang ada. Selanjutnya ia dapat menerapkan solusi tersebut untuk mengatasi masalah yang dihadapi. Gray, et al., (2015) menyatakan bahwa proses merancang dan mengembangkan pembelajaran, dipengaruhi oleh beberapa komponen sebagai berikut :

a) Kemampuan awal peserta didik dan potensi yang dimiliki.

b) Tujuan Pembelajaran (umum dan khusus) adalah penjabaran kompetensi yang akan dikuasai oleh peserta didik.

c) Analisis materi pembelajaran yang digunakan untuk mencapai tujuan pembelajaran.

d) Analisis aktivitas pembelajaran, merupakan proses menganalisis topik atau materi yang akan dipelajari.

e) Pengembangan media pembelajaran yang sesuai dengan tujuan, materi pembelajaran dan kemampuan peserta didik.

f) Strategi pembelajaran, dapat dilakukan secara makro dalam kurun satu tahun atau mikro dalam kurun satu kegiatan belajar mengajar.

g) Sumber belajar, adalah sumber-sumber yang dapat diakses untuk memperoleh materi yang akan dipelajari.

h) Penilaian belajar, tentang pengukuran kemampuan atau kompetensi yang dikuasai oleh peserta didik.

Evaluasi adalah langkah selanjutnya, sehingga nantinya bisa mengetahui rancangan yang sesuai dengan pembelajaran dan rancangan tersebut bisa diaplikasikan dalam proses pembelajaran (Oliver, et al., 2018; Machado, et. al., 2018). Penilaian tentang kinerja guru dalam merancang pembelajaran menjadi penting ketika sekolah akan melakukan reposisi (Campbell and Ronfeldt, 2018). Artinya bagaimana sekolah harus mengetahui faktor-faktor apa saja yang mempengaruhi kinerja tersebut. Hasil analisis akan bermanfaat untuk membuat program pengembangan SDM secara optimum. Pada gilirannya kinerja guru ini akan mencerminkan derajat kompetisi suatu sekolah. Maju dan mundurnya suatu sekolah sangat dipengaruhi oleh kinerja dari guru yang ada di sekolah tersebut yang salah satunya terkait dengan learning design skills. Penilaian kinerja guru dalam hal ini menjadi tugas utama dari pengawas sekolah yang ditunjuk.

Keterampilan utama dari seorang Pengawas adalah melakukan penilaian dan pembinaan (academic spuervision) kepada guru untuk secara terus menerus meningkatkan kualitas proses pembelajaran yang dilaksanakan di kelas agar berdampak pada kualitas hasil belajar siswa. Pengawas diharapkan dapat melakukan pengawasan akademik yang didasarkan pada metode dan teknik supervisi akademik yang tepat sesuai dengan kebutuhan guru untuk dapat mencapai kompetensi tersebut.

Supervisi akademik adalah kemampuan pengawas dalam melaksanakan pengawasan akademik yakni menilai dan membina guru dalam rangka mempertinggi kualitas proses pembelajaran yang dilaksanakannya, agar berdampak terhadap kualitas hasil belajar siswa. Supervisi akademik intinya adalah membina guru dalam meningkatkan mutu proses pembelajaran. Oleh karena itu, sasaran supervisi akademik adalah guru dalam proses 
pembelajaran, yang terdiri dari materi pokok dalam proses pembelajaran, penyusunan silabus dan RPP, pemilihan strategi/metode/teknik pembelajaran, penggunaan media dan teknologi informasi dalam pembelajaran, menilai proses dan hasil pembelajaran serta penelitian tindakan kelas. Oleh karena itu tujuan umum pembinaan pengawas melalui supervisi akademik ini adalah (1) menerapkan teknik dan metode supervisi akademik di sekolah, dan (2) Mengembangkan kemampuan dalam menilai dan membina guru untuk mempertinggi kualitas proses pembelajaran yang dilaksanakannya agar berdampak terhadap kualitas hasil belajar siswa.

Berdasarkan analisis pendahuluan di atas dipandang perlu untuk melakukan tindakan melalui academic supervision sebagai kontrol kinerja dalam rangka meningkatkan learning design skills dari guru-guru khususnya di sekolah dasar binaan (Gan and Yang, 2018; Prasetyono, et al., 2018). Deskripsi action dalam penelitian ini menjabarkan tentang dampak academic supervison terhadap kinerja guru dalam proses perancangan pembelajaran yang berkualitas dan sesuai dengan prosedur yang tepat.

\section{Metode Penelitian}

Penelitian ini merupakan penelitian tindakan (action reseacrh) yang diakukan melalui tiga siklus yang direncanakan. Pelaksanaa tindakan ini dilakukan dengan teknik academic supervision untuk meningkatkan learning design skills guru-guru di sekolah dasar binaan. Rancangan tiga siklus tindakan yang direncanakan mengacu pada Nurwahida (2018) dan ditampilkan pada Gambar 1 berikut.

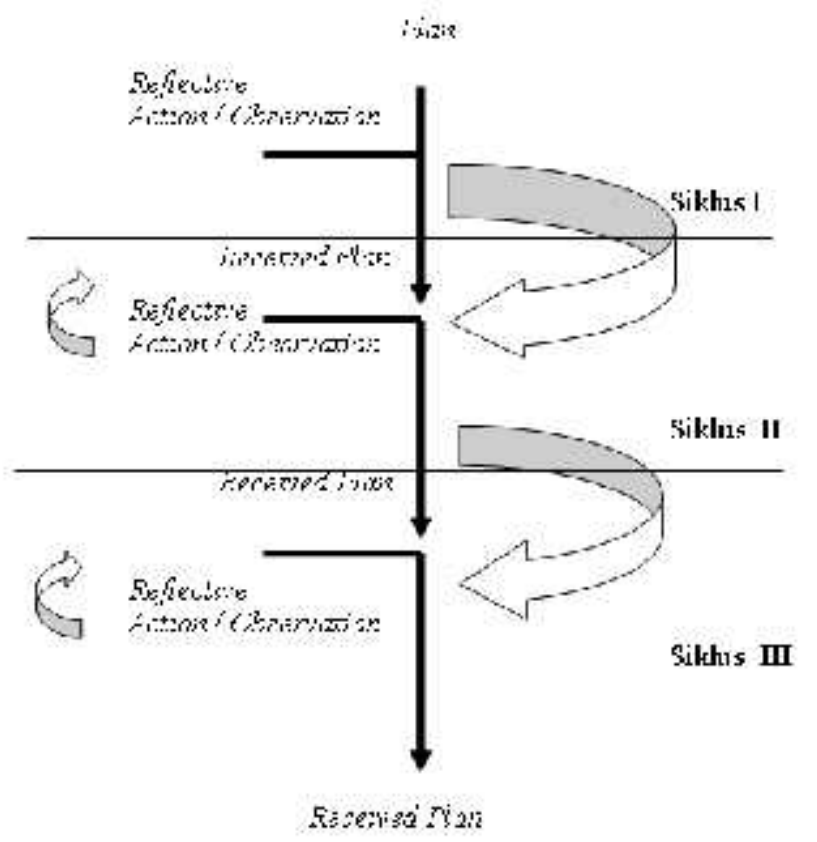

Gambar 1. Alur Penelitian Tindakan Berbasis Kepengawasan

Subjek dalam penelitian ini adalah Guru SD Binaan Wilayah Kec. Batukliang Utara Kabupaten Lombok Tengah yang merupakan sekolah yang merupakan sekolah binaan tahun 2019. Jumlah guru yang dilibatkan yakni 17 orang yang terdiri dari guru tetap (GT) maupun guru tidak tetap (GTT) dan berasal dari 11 Sekolah Dasar. Pengumpulan data terkait dengan academic supervision dalam ini dilakukan dengan tiga teknik yakni a) teknik kunjungan kelas, b) observasi kelas, dan c) pertemuan individual. Data yang dikumpulkan di analisis dengan membandingkan persentase standar ketuntasan dari learning design skills guru-guru 
sekolah dasar pada setiap siklus. Persentase skor rata-rata learning deisgn skills guru yang diharapkan adalah minimal sebesar $85 \%$. Adapun kriteria ketuntasan dari learning design skills dalam hal ini mengacu pada Tabel 1 berikut.

\section{Tabel 1. Kriteria Ketuntasan Learning design skills}

\begin{tabular}{c|c}
\multicolumn{2}{c}{ Tabel 1. Kriteria Ketuntasan Learning design skills } \\
Skor Persentase Ketuntasan (K) & Kriteria Ketuntasan \\
\hline $85 \nVdash \leq 100$ & Tuntas \\
$K>85$ & Tidak Tuntas (perlu bimbingan) \\
\hline
\end{tabular}

\section{Hasil Penelitian dan Pembahasan}

Penelitian ini menggunakan model pembinaan melalui academic supervision sebagai upaya untuk meningkatkan kinerja guru dalam perancangan pembelajaran. Tujuan yang diharapkan dalam tindakan ini adalah untuk meningkatkan kinerja guru dalam perancangan pembelajaran. Adapun hasil yang diperoleh dalam setiap siklus tindakan ditampilkan pada Tabel 2 berikut.

Tabel 2. Persentase dan Kriteria Ketuntasan Learning Design Skills

\begin{tabular}{cccc}
\hline \multirow{2}{*}{ Siklus } & \multicolumn{2}{c}{ Ketuntasan Guru SD (\%) } & \\
\cline { 2 - 4 } & Tuntas & Tidak Tuntas & Rata-rata skor ketuntasan (\%) \\
\hline I & 41,17 & 58,83 & 68,53 \\
II & 64,71 & 35,29 & 77,94 \\
III & 100 & 0 & 85,29 \\
\hline
\end{tabular}

Pengamatan dilaksanakan bersamaan dengan pelaksanaan proses belajar mengajar di sekolah. Pada akhir proses pembinaan guru diberi angket isian I dengan tujuan untuk mengetahui tingkat kinerja guru dengan pedoman yang telah dilakukan. Adapun data hasil penelitian pada siklus I seperti ditampilkan pada Tabel 2.

Data pada Tabel 2 di atas dapat dijelaskan bahwa dengan pembinaan yang dilakukan oleh pengawas melalui academic supervision diperoleh nilai rata-rata peningkatan kinerja guru adalah 68,53 \%. Hasil tersebut menunjukkan bahwa pada siklus pertama secara kelompok ( guru ) belum meningkat peran dan fungsinya, karena yang memperoleh nilai $\geq 75$ hanya sebesar $41,18 \%$ atau ada 7 orang guru dari 17 orang sudah tuntas, hasil ini lebih kecil dari persentase ketuntasan yang dikehendaki yaitu sebesar $85 \%$. Hal ini disebabkan karena banyak guru yang belum familier dengan tugasnya sehingga mereka belum dapat memahaminya dengan baik.

Pada pelaksanaan kegiatan pembinaan pada siklus I ini masih terdapat kekurangan, sehingga perlu adanya revisi untuk diperbaiki pada siklus berikutnya. Beberapa perbaikan yang dipertimbangkan oleh supervisor pada siklus II adalah sebagai berikut:

1) Supervisor perlu lebih terampil dalam memotivasi guru dan lebih jelas dalam menyampaikan tujuan pembinaan, dimana guru diajak untuk terlibat langsung dalam setiap kegiatan yang akan dilakukan.

2) Supervisor perlu mendistribusikan waktu dengan baik dengan menambahkan informasiinformasi yang dirasa perlu dan memberi catatan

3) Supervisor harus lebih terampil dan bersemangat dalam memotivasi guru sehingga guru bisa lebih antusias.

Proses pembinaan mengacu pada rencana pembinaan dengan memperhatikan revisi pada siklus I ini, sehingga kesalahan atau kekurangan pada siklus I tidak terulang lagi pada siklus II. Penelitian tindakan melalui academic supervision ini dilaksanakan sesuai dengan prosedur rencana pembinaan dan skenario pembinaan dan dilaksanakan pada saat proses belajar mengajar berlangsung. 
Hasil yang diperoleh pada siklus II terkait dengan nilai rata-rata peningkatan kinerja guru adalah $77.94 \%$ dan peningkatan kinerja guru mencapai $64.71 \%$ atau ada 11 orang dari 17 orang guru yang sudah tuntas dalam meningkatkan kinerjanya. Hasil ini menunjukkan bahwa peningkatan kinerja guru telah mengalami peningkatan sedikit lebih baik dari siklus I. Adanya peningkatan kinerja guru ini karena setelah pengawas menegaskan adanya penilaian di akhir proses pembelajaran, sehingga guru lebih termotivasi untuk meningkatkan kinerjanya. Selain itu juga, para guru sudah mulai mengerti apa maksud dan tujuan dari pembinaan di sekolah. Walaupun terdapat peningkatan nilai rata-rata learning design skills guru-guru dibandingkan pada siklus I, namun nilai rata-rata ini belum dikatakan tuntas, karena kurang dari $85 \%$. Artinya, bahwa masih diperlukan action dalam meningkatkan learning design skills guru-guru sekolah dasar binaan.

Hasil evaluasi pada siklus II, ditemukan beberapa kekurangan-kekurangan yang harus dipertimbangkan untuk melakukan action pada siklus berikutnya. Adapun kekurangankekurangan tersebut diantaranya adalah sebagai berikut:

1) Pembinaan kepada guru hendaknya dapat membuat para guru termotivasi dalam meningkatkan learning design skills.

2) Pembinaan hendaknya dilakukan dengan personal approach untuk meningkatkan self confidence dan self-efficacy mereka dalam menyelesaikan masalah yang dihadapi.

3) Supervisor hendaknya menambah lebih banyak contoh-contoh program kerja dengan format format yang sudah distandardisasi oleh Departemen Pendidikan, dalam hal ini Lembaga Penjaminan Menyusun rancangan pembelajaran ( LPMP ) baik di Tingkat Provinsi maupun tingkat Pusat.

Berdasarkan temuan kekurangan-kekurangan pada siklus II tersebut, maka diperlukan action lanjutan yakni pada siklus III untuk memperbaikinya. Hasil action pada siklus III yang ditampilkan pada Tabel 2 di atas diperoleh nilai rata-rata tes formatif sebesar $85.29 \%$ dan dari 17 orang guru secara keseluruhan sudah mencapai ketuntasan dalam meningkatkan peran dan fungsinya, maka secara keseluruhan ketuntasan telah mencapai $100 \%$ (termasuk kategori tuntas). Hasil pada siklus III ini mengalami peningkatan lebih baik dari siklus II. Adanya peningkatan hasil belajar pada siklus III ini dipengaruhi oleh adanya peningkatan kemampuan pengawas dalam menerapkan pembinaan melalui supervisi akademik Pengawas sehingga guru menjadi lebih memahami tugasnya dan dapat meningkatkan learning design skills. Selain itu, ketuntasan ini juga dipengaruhi oleh kerjasama dari pengawas dengan guru dalam melaksanakan program sekolah.

Berdasarkan Permen No 13 Tahun 2007 tentang kompetensi Pengawas bahwa kriteria ketuntasan yang diharapkan terkait dengan learning deisgn (membuat rencana kerja pembelajaran, serta mengorganisasikan sekolah kearah perubahan yang diinginkan) dikatakan efektif jika minimal nilai rata-rata skor ketercapaiannya mencapai $85 \%$.

\section{Kesimpulan}

Kesimpulan yang diperoleh bahwa penelitian tindakan berbasis academic supervision ini memiliki dampak positif dalam meningkatkan kinerja guru dalam menyusun rancangan pembelajaran, hal ini dapat dilihat dari semakin mantapnya pemahaman guru terhadap pembinaan yang disampaikan supervisor pada siklus I, II, dan III yaitu masing-masing 68.53 $\% ; 77.94 \% ; 85.29 \%$. Penerapan academic supervision ini berlangsung pada tiga siklus untuk memperoleh kategori tuntas terhadap peningkatan learning design skills semua guru-guru binaan di sekolah dasar. 


\section{Saran}

Saran yang dapat disampaikan berdasarkan hasil penelitian ini adalah agar Guru-guru binaan diharapkan dapat menggunakan hasil kajian ini sebagai referensi untuk meningkatkan kemampuan dalam mendesain pembelajaran yang menarik dan interaktif.

\section{Daftar Pustaka}

Persico, D., Passarelli, M., Manganello, F., Gewerc Barujel, A., \& Rodriguez Groba, A. (2020). The participatory dimension of teachers' self-regulated professional learning about learning design: beliefs versus behaviours. Professional Development in Education, 1-13.

Dagnino, F. M., Dimitriadis, Y. A., Pozzi, F., Asensio-Pérez, J. I., \& Rubia-Avi, B. (2018). Exploring teachers' needs and the existing barriers to the adoption of Learning Design methods and tools: A literature survey. British Journal of Educational Technology, 49(6), 998-1013.

Habibi, Jumadi, Mundilarto, Yanti, F. A. (2019, February). Learning design: reflective video as self-control in project learning for physics teacher candidates. In Journal of Physics: Conference Series (Vol. 1153, No. 1, p. 012118). IOP Publishing.

Ma, N., Xin, S., \& Du, J. Y. (2018). A peer coaching-based professional development approach to improving the learning participation and learning design skills of inservice teachers. Journal of Educational Technology \& Society, 21(2), 291-304.

Sugiri, W. A., Priatmoko, S., \& Basori, B. (2020). Flipped classroom learning design using the ASSURE model. Teknodika, 18(2), 124-132.

West, R. E., Thomas, R. A., Bodily, R., Wright, C., \& Borup, J. (2018). An analysis of instructional design and technology departments. In Educational media and technology yearbook (pp. 3-24). Springer, Cham.

Gray, C. M., Dagli, C., Demiral-Uzan, M., Ergulec, F., Tan, V., Altuwaijri, A. A., ... \& Boling, E. (2015). Judgment and instructional design: How ID practitioners work in practice. Performance Improvement Quarterly, 28(3), 25-49.

Oliver, A., Odena, A., Raffel, C., Cubuk, E. D., \& Goodfellow, I. J. (2018). Realistic evaluation of deep semi-supervised learning algorithms. arXiv preprint arXiv:1804.09170.

Machado, M. C., Bellemare, M. G., Talvitie, E., Veness, J., Hausknecht, M., \& Bowling, M. (2018). Revisiting the arcade learning environment: Evaluation protocols and open problems for general agents. Journal of Artificial Intelligence Research, 61, 523562.

Campbell, S. L., \& Ronfeldt, M. (2018). Observational evaluation of teachers: Measuring more than we bargained for?. American Educational Research Journal, 55(6), 12331267.

Gan, Z., \& Yang, C. C. R. (2018). How prepared are the preservice ESL teachers to teach: Insights from university supervisor feedback. Journal of Asia TEFL, 15(1), 99.

Prasetyono, H., Abdillah, A., \& Fitria, D. (2018). Academic supervision toward teacher's performance through motivation as intervening variable. Journal of Education and Learning (EduLearn), 12(2), 188-197.

Nurwahida, N. (2018). Effort Increasing Learning Result Of Geography Through Project Based Learning Model In The Basic Knowledge Of Mapping Material At Class X Mipa 5 In Sman 2 Padang. Jurnal Kapita Selekta Geografi, 1(3), 115-121 